- cites an example from 2015, when Spanish surgeons needed a replacement ribcage for a patient with a tumour growing in his chest wall. The scientists asked Melbourne firm Anatomics to design it, uploading their patient's computed tomography scans directly to the company. The ribcage was printed in Clayton, at the centre for the Commonwealth Scientific and Industrial Research Organisation, the national research agency.

Science isn't the only thing to recommend Melbourne. The city has topped The Economist's index of the world's most liveable cities for the past six years (see 'A career in coffee').

If you look up almost anywhere in Australia, you'll be greeted by a clear, radio-quiet night sky, says Alan Duffy, an astronomer at Swinburne who moved to Australia in 2009 from the Jodrell Bank Centre for Astrophysics in Manchester, UK. "Australia always seemed like this incredible exotic land," Duffy says. "Scientifically, at least in astronomy, it is one of the top countries."

Last year, Swinburne won Australian Research Council funding to establish a new Centre of Excellence for Gravitational Wave Discovery. And, with state government support, Swinburne and Melbourne universities have installed the Southern Hemisphere's first dark-matter detector - housed in Victoria in a gold mine, a kilometre underground, to protect it from interference from atmospheric particles.

Swinburne's strength in the emerging field of data science will be crucial for the project. The astronomers need computer scientists to develop ways to handle astronomically sized data sets. "It's given rise to a really exciting new discipline - the skills used to explain exploding stars can be used to understand issues such as traffic management," Duffy says.

"Melbourne prides itself on creation and creativity, and you can see that - from the artistry we put into preparing coffee, to the way people dress, to the fact that public talks on the most esoteric scientific matters are sell-outs."

"Melbourne is a melting pot of ideas and a very innovative place to live and work in," O'Connell agrees. "It's a great place to live in general - there's a great art scene, a music scene, a beautiful seafront."

"I've known many astronomers who would rather leave astronomy than leave Melbourne," Duffy says. "I always look forward to coming back here." -

James Mitchell Crow is a science writer based in Melbourne.

\title{
THE FINE PRINT
}

\section{What you need to know}

Australia's Temporary Work (Skilled) visa system is currently in flux after the Australian government announced an overhaul in April. Most researchers coming to Australia have used this visa, which allows skilled workers with dependents to work in their chosen field for up to four years. Applicants may be sponsored by an employer or considered a good fit for an open position.

The Temporary Work (Skilled) visa costs start at Aus $\$ 2,120$ (US\$1,636) and applications were usually processed within 90 days. After two years on this visa, sponsored workers and their dependents could be nominated for a permanent residency visa by their employer. These rules are being changed gradually, with a full overhaul due in March 2018.

Another option is the Skilled Independent visa (subclass 189). This is aimed at English-speaking applicants under the age of 50 who are qualified to fill positions relevant to the country's skill shortage list, but who are not sponsored by an employer. The price starts at Aus $\$ 3,600$ and the visa is assessed under a pointsbased system. Successful applicants can stay in Australia permanently.

Use the Australian government's Visa Finder page (www.border.gov.au/ Trav/Visa-1) to stay up to date.

\section{OPPORTUNITIES \& CONTACTS}

International Postgraduate Research Scholarships provide tuition fees and health cover for two years for master's degrees and three years for doctoral degrees. Melbourne's bigger universities also offer their own postgraduate scholarships.

Commonwealth Scientific and Industrial Research Organisation postdoctoral fellowships are available for $\mathrm{PhD}$ graduates with no more than three years of postdoc experience.

The National Health and Medical Research Council offers five-year fellowships for health and medical researchers.

The Australian Research Council offers three-year Discovery Early Career Researcher Awards to scientists within five years of being awarded a PhD. J.M.C.

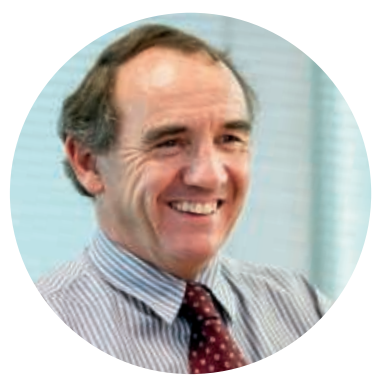

\section{JIM McCLUSKEY}

Cosmopolitan Melbourne has changed dramatically since Jim McCluskey's last stint in the city - he worked as a researcher at Monash University between 1987 and 1990. McCluskey returned in 1997 as chair of microbiology and immunology at the University of Melbourne, and became deputy vice-chancellor (research) in 2011. A native of Perth, where he studied medicine, he has also worked in Adelaide and Washington DC.

\section{What is it like working at the} University of Melbourne?

We're surrounded by five major public hospitals, four independent research institutes and a large number of nongovernmental organizations and agencies. The Royal Melbourne Institute of Technology University is a few hundred yards away. Ten thousand biomedical researchers work here.

You go for coffee, bump into people and have great conversations. We have around

20,000 international students (we have approximately 50,000 overall), and there are roughly 120 languages spoken on campus.

What attracts researchers to Melbourne?

There are great collaborations across disciplines. We also have the 'two-body opportunity' when someone's partner also needs a job, and having this diverse workforce means you can map jobs to skills much better. There are great schools and a growing public transport system. If there's a downside, it's expensive property prices.

\section{What's the city like?}

It is globally connected, cosmopolitan and dynamic, with great neighbourhoods, restaurants, theatres and music. The Yarra Valley wineries are nearby. My family and I spend a lot of time enjoying Port Phillip Bay. We have a weekend property just over an hour away. We're surrounded by birds and kangaroos there. When I get fed up reading academic board papers, I climb on the mower and cut the grass. It's a very Zen activity. At night the sky is inky and dotted with stars. It's wonderful. 